\title{
Research of the Residual Bearing Capacity and the Work of Damaged Reinforced Concrete Beams' Inclined Sections
}

\author{
Zeljko Kos*, Yevhenii Klymenko, Kostiantyn Polianskyi, Andjelko Crnoja
}

\begin{abstract}
The article is devoted to studies about the stress-strain state and the residual bearing capacity of inclined sections of reinforced concrete beams with concrete damages in the compressed zone near support areas. The developed method of calculating the bearing capacity of the inclined sections of damaged beams is described. The numerical test of prototypes was performed in the LIRA-CAD 2017 software complex. A comparison of the results of laboratory tests, a numerical experiment and calculation results by the proposed method is shown. It is stressed that with an increase in the area of damage, the bearing capacity decreases. The nature of the change in the stress-strain state under the presence of damage is described. It is pointed out that in the damaged samples, there is an inclination of the neutral axis in the cross section of the element - it tilts, the neutral axis becomes, almost, parallel to the front of the damage.
\end{abstract}

Keywords: damaged RC beams; inclined section; method of calculation; residual bearing capacity; stress-strain state

\section{INTRODUCTION}

Reinforced concrete is a relatively durable material and may serve for a long time. Its active use began in the first half of the last century and continues to this day. The buildings and structures constructed at that time can be operated to this day. Over time, damages can appear and defects may be present. Damage can occur from various factors. Bonić $Z$. et al. [1] note the occurrence of damage from construction errors, the action of an aggressive atmosphere (which leads to the corrosion of concrete and reinforcement); Lu Z. et al. [2] note the occurrence of damage from exposure to elevated temperatures (in particular due to fires); Hayashi T, et al. [3, 4] note the occurrence of damage from accidental effects of freeze-thaw cycles; and etc.

Unfortunately, in the current codes $[5,6]$, there are no methods and guidelines for determining the residual bearing capacity of damaged elements. Due to the lack of guidance in the construction practice, when conducting a structural inspection, the decision to reinforce damaged elements is often applied intuitively, although the bearing capacity of such elements may still be provided.

A significant amount of work has been devoted to the study of reinforcing damaged elements. In particular, Kabir M. et al. [7] investigated the operation of reinforced beams by using CFRP; Burningham $C$. et al. [8] investigated the operation of reinforced beams by using the Steel Tendons Using Post-Tensioned Carbon Fiber-Reinforced Polymer Rods; Hou L. et al. [9] investigated the operation via reinforced beams repaired with ultra-high toughness cementitious composite.

There is a number of works on the probabilistic assessment of the reliability of damaged elements, among which Sakka, Z. et al. [10] can be noted, where the author proposed a technique using a probabilistic analysis of the statistics of random variables.

A number of studies were carried out by Klimenko E. et al. $[11,12]$ to determine the bearing capacity of damaged elements, as well as methods for calculating damaged compressed concrete columns and bent beams from a normal section, it was also noted that changes occur due to a damage stress-strain state.

However, in all available literary sources, the determination of the residual bearing capacity by the inclined sections in the damaged beams was not found.

\subsection{The Aim of the Work}

The aim of the study is to obtain experimental data on the stress-strain state, the residual bearing capacity of the inclined sections of the damaged beams and the development of methods for revising calculations.

\subsection{Materials and Characteristics of Experimental Samples}

For the experiment, 15 samples were made. The materials for the samples were: concrete - grade of $\mathrm{C} 25 / 30$ working longitudinal reinforcement - grade of A500C $\varnothing 18$ $\mathrm{mm}$, the vertical shear reinforcement in the form of closed clamps and structural reinforcement - grade of A240C $\varnothing 6$ $\mathrm{mm}$. Reinforcement was designed so that the destruction occurred along an inclined section within the considered shear span. The cross-sectional size of the elements is $100 \times$ $200 \mathrm{~mm}$, length is $1200 \mathrm{~mm}$, the working span of $1000 \mathrm{~mm}$, the bearing is free.

The loading of the samples was in the form of a concentrated force $F_{u}$ with uniformly increasing steps. The influence of three factors on the bearing capacity is studied the shear span, the depth of damage and the angle of the inclination of the damage. Therefore, artificial damage to the compressed zone of the concrete of various depths $h_{1}(0,50$ and $100 \mathrm{~mm})$ and the inclination angle $\beta_{1}\left(0^{\circ}, 30^{\circ}, 60^{\circ}\right)$ were placed in the samples, and the load was applied at a relative shear span of $a_{v} 1 d, 2 d$, and $3 d$. The characteristics of samples are shown in Tab. 1 and in Fig. 1. 


\section{RESULTS OF LABORATORY TESTS}

\subsection{The Nature of the Destruction, Cracking and Deflection of Samples}

During testing, all samples were destroyed by an inclined section because of the prevailing action of the transverse force, and as a rule, inclined cracks were significantly revealed in the samples and concrete was destroyed above the crack top. The angle of the tilt of the inclined crack was up to $22^{\circ}$ at $a_{v}=510 \mathrm{~mm}$, up to $30^{\circ}$ at $a_{v}=340 \mathrm{~mm}$, and up to $60^{\circ} a_{v}=170 \mathrm{~mm}$. The appearance of normal visible cracks fixed at 1-2 step loading is earlier than the inclined cracks. Visible inclined cracks along the undamaged face appeared 1-2 steps earlier than the damaged one, and they also had a greater length and width of the opening up to the penultimate or the last stage of loading, and they had a width of 0.4-0.5 $\mathrm{mm}$.

The data of the ultimate deflections $f_{\mathrm{u}}$ showed that a reduction of the shear span, and an increase of the damaged area mainly leads to their reduction. The values of the obtained ultimate deflections in the experimental samples are shown in Tab. 2.

Table 1 Variable characteristics for samples

\begin{tabular}{|c|c|c|c|}
\hline $\begin{array}{c}\text { Call } \\
\text { number }\end{array}$ & $\begin{array}{c}\text { Depths of damage } \\
h_{1}, \mathrm{~mm}\end{array}$ & $\begin{array}{c}\text { Angle of damage } \\
\beta_{1},{ }^{\circ}\end{array}$ & $\begin{array}{c}\text { Shear span } \\
a_{\mathrm{v}}, \mathrm{mm}\end{array}$ \\
\hline B1 & 0 & 0 & $3 \mathrm{~d}$ \\
\hline B2 & 50 & 30 & $3 \mathrm{~d}$ \\
\hline B3 & 50 & 60 & $3 \mathrm{~d}$ \\
\hline B4 & 100 & 30 & $3 \mathrm{~d}$ \\
\hline B5 & 100 & 60 & $3 \mathrm{~d}$ \\
\hline B6 & 0 & 0 & $2 \mathrm{~d}$ \\
\hline B7 & 50 & 30 & $2 \mathrm{~d}$ \\
\hline B8 & 50 & 60 & $2 \mathrm{~d}$ \\
\hline B9 & 100 & 30 & $2 \mathrm{~d}$ \\
\hline B10 & 100 & 60 & $2 \mathrm{~d}$ \\
\hline B11 & 0 & 0 & $1 \mathrm{~d}$ \\
\hline B12 & 50 & 30 & $1 \mathrm{~d}$ \\
\hline B13 & 50 & 60 & $1 \mathrm{~d}$ \\
\hline B14 & 100 & 30 & $1 \mathrm{~d}$ \\
\hline B15 & 100 & 60 & $1 \mathrm{~d}$ \\
\hline
\end{tabular}

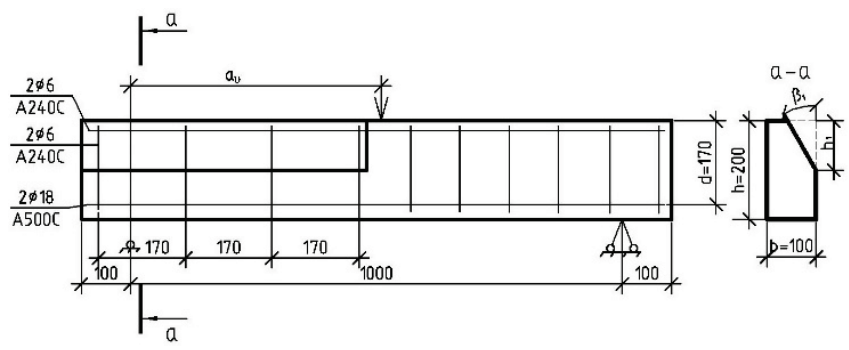

Figure 1 Characteristics of samples

\subsection{Bearing Capacity of Samples}

From the obtained laboratory data, it can be said that the bearing capacity decreases with an increase in the area of damage and the shear span. Within each shear span, specimens with a larger damage area are able to perceive less transverse force; specimens with a lower damage height and a greater angle of inclination are able to perceive a greater load than the samples with a larger damage height and a smaller inclination angle.
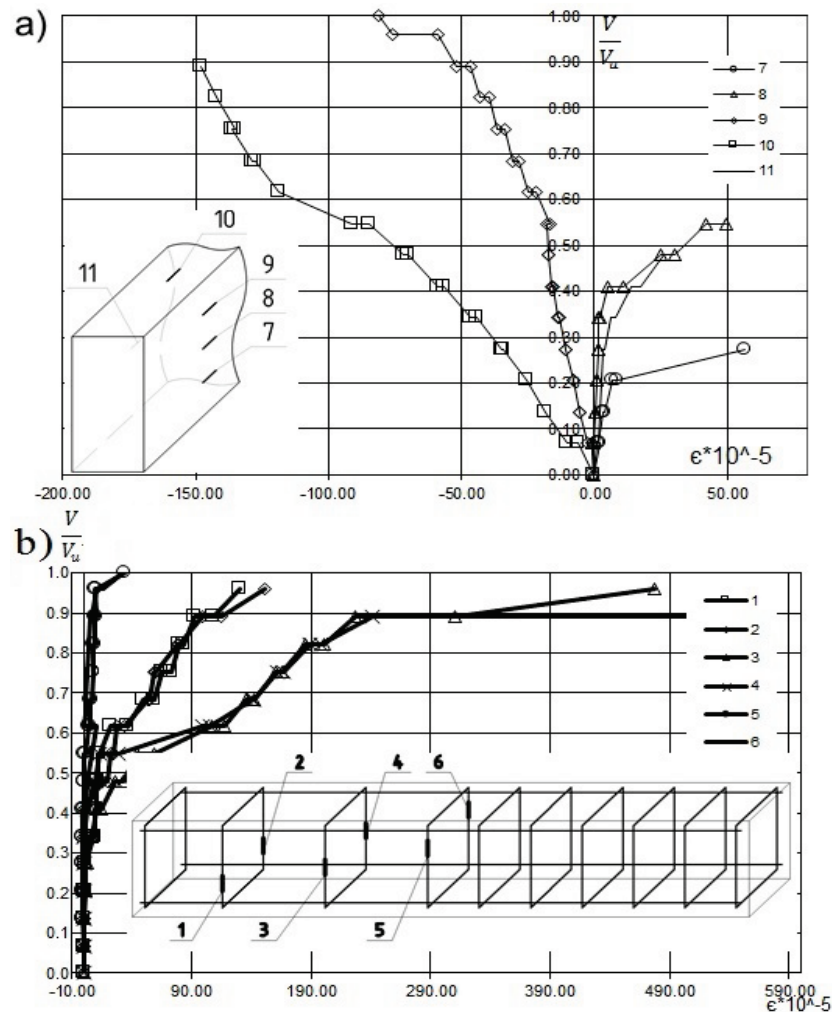

Figure 2 Nature of the strain state of the undamaged sample B1: (a) deformations of concrete and $(b)$ deformations of transverse reinforcement

Table 2 Data of the ultimate deflections and ultimate deformations in experimental samples

\begin{tabular}{|c|c|c|c|}
\hline $\begin{array}{c}\text { Call } \\
\text { number }\end{array}$ & $\begin{array}{c}\text { Ultimate } \\
\text { deflections } f_{\mathrm{u}} \text { at } \\
\approx 0.95 \cdot F_{\mathrm{u}} \mathrm{mm}\end{array}$ & $\begin{array}{c}\text { Ultimate concrete } \\
\text { deformation } \\
\varepsilon_{\mathrm{c}}^{\mathrm{u}} \times 10^{-5}\end{array}$ & $\begin{array}{c}\text { Ultimate shear } \\
\text { reinforcement } \\
\text { deformation } \\
\varepsilon_{\mathrm{sw}}^{\mathrm{u}} \times 10^{-5}\end{array}$ \\
\hline B1 & 4.94 & 148 & 512 \\
\hline B2 & 4.03 & 283 & 323 \\
\hline B3 & 4.5 & 401 & 402 \\
\hline B4 & 4.68 & 377 & 287 \\
\hline B5 & 2.37 & 200 & 36 \\
\hline B6 & 3.92 & 163 & 712 \\
\hline B7 & 2.89 & 119 & 302 \\
\hline B8 & 2.88 & 177 & 285 \\
\hline B9 & 2.4 & 150 & 204 \\
\hline B10 & 2.59 & 152 & 24 \\
\hline B11 & 3.3 & 41 & 260 \\
\hline B12 & 2.04 & 49 & 184 \\
\hline B13 & 1.95 & 86 & 41 \\
\hline B14 & 2.45 & 45 & 64 \\
\hline B15 & 2.01 & 69 & 144 \\
\hline
\end{tabular}

The bearing capacity at the shear span of $a_{v}=510 \mathrm{~mm}$ in the damaged samples of B2, B3, B4, B5 is $95.94 \%, 80.82 \%$, $79.46 \%, 41.0 \%$ (respectively) of the bearing capacity of the sample B1; at the shear span of $a_{v}=340 \mathrm{~mm}$ in the damaged samples of B7, B8, B9, B10 is $74.98 \%, 69.99 \%, 54.99 \%$, $42.5 \%$ of the bearing capacity of the sample B6; at the shear span of $a_{v}=170 \mathrm{~mm}$ in the damaged samples of B12, B13, $\mathrm{B} 14, \mathrm{~B} 15$ is $94.74 \%, 88.42 \%, 78.95 \%, 67.31 \%$ of the bearing 
capacity of the sample B11. The results of the bearing capacity are shown in Tab. 3.

Table 3 Data of the bearing capacity according to the results of laboratory tests, numerical experiment and calculation by the proposed method.

\begin{tabular}{|c|c|c|c|}
\hline $\begin{array}{c}\text { Call } \\
\text { number }\end{array}$ & $\begin{array}{c}\text { Bearing capacity } \\
\text { of the laboratory } \\
\text { tests } V_{\text {exp }}^{\mathrm{u}}, \mathrm{kN}\end{array}$ & $\begin{array}{c}\text { Bearing capacity } \\
\text { of the numerical } \\
\text { tests } V_{\text {LIRA }}^{\mathrm{u}}, \mathrm{kN}\end{array}$ & $\begin{array}{c}\text { Bearing capacity } \\
\text { of the calculations } \\
V_{\text {calculated }}^{\mathrm{u}} \mathrm{kN}\end{array}$ \\
\hline B1 & 59.54 & 54.51 & 54.16 \\
\hline B2 & 57.14 & 51.74 & 51.85 \\
\hline B3 & 48.16 & 44.51 & 47.23 \\
\hline B4 & 47.35 & 43.39 & 44.92 \\
\hline B5 & 24.49 & 22.64 & 31.38 \\
\hline B6 & 87.98 & 81.97 & 69.36 \\
\hline B7 & 65.97 & 80.13 & 66.4 \\
\hline B8 & 61.58 & 52.67 & 60.49 \\
\hline B9 & 48.38 & 51.48 & 57.53 \\
\hline B10 & 37.39 & 32.71 & 44.83 \\
\hline B11 & 131.36 & 113.3 & 133.4 \\
\hline B12 & 124.45 & 110.06 & 127.7 \\
\hline B13 & 116.15 & 103.58 & 116.3 \\
\hline B14 & 103.7 & 100.35 & 110.6 \\
\hline B15 & 88.5 & 72.09 & 77.29 \\
\hline$v, \%$ & & 14.81 & 10.3 \\
\hline
\end{tabular}

\subsection{Nature of the Strain State of Samples}

During laboratory tests, data were obtained on the ultimate deformations of the concrete $\varepsilon_{\mathrm{c}}^{\mathrm{u}}$ and transverse reinforcement $\varepsilon_{\mathrm{sw}}^{\mathrm{u}}$. The data are presented in Tab. 2 .

By analyzing the data, it can be concluded that the ultimate deformations of concrete decrease when the shear span decreases. An increase in the angle of damage leads to an increase in the ultimate deformation. The character of deformation indicates that the position of the neutral axis is tilted in damaged elements.

The final deformations of the transverse reinforcement and concrete are reduced with a decrease in the shear range. With an increase in the area of damage to the beams, the limiting deformations also reach lower values. It was noticed that at the initial stages of loading, the bars of transverse reinforcement are slightly compressed, but with an increase in load by several steps, they begin to experience tension. Another feature is that the bars located at the intact face had large deformations.

The character of the deformations of concrete and transverse reinforcement is shown in Figs. 2 and 3. Deformations were determined by using strain gauges; therefore, when the line breaks, it means that either the strain gauge is out of order, or that the strains reached values higher than the sensitivity of the measuring device.

\section{RESULTS OF THE NUMERICAL EXPERIMENT}

A simulation of the experimental samples was performed in the LIRA-CAD software complex based on the finite element method. An iterative calculation of nonlinear steps is performed. For the calculation, the actual stress-strain $\sigma-\varepsilon$ diagrams were used. The criterion for the destruction of the samples was to one or several conditions: stresses in the compressed concrete have to reach ultimate values, stresses in the reinforcement have to reach ultimate values, there have to be significant fast-growing movements (more than $10 \mathrm{~mm}$ ) of the elements of the design scheme.

The obtained data on the residual bearing capacity are shown in Tab. 3.

In general, the bearing capacity data showed good convergence with the results of laboratory studies, as evidenced by the coefficient of variation $v=14.81 \%$.

Analyzing the character of destruction of the destruction of elements, it can be seen that it corresponds to the nature of the destruction during laboratory tests (destruction of concrete over the top of the inclined crack), but B1...B14 samples survived destruction due to the destruction of concrete on a support, which does not correspond to the tests.

The data of concrete deformation, as well as laboratory test data, show that the neutral axis tilts in the damaged samples - it becomes almost parallel to the damage front. A comparison of the position of the neutral axis of the cross section of the samples obtained in the simulation and in the laboratory test is shown in Fig. 4.
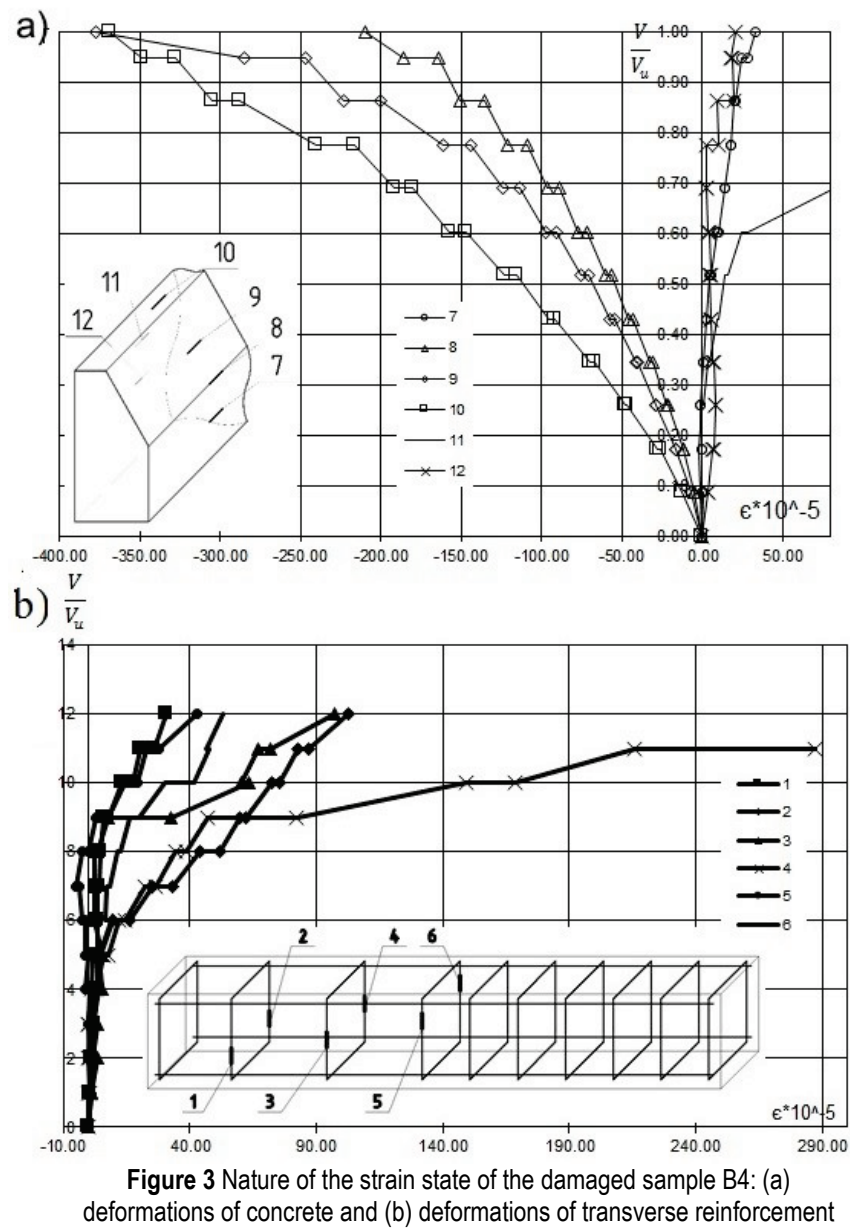

The stress analysis in the bars of transverse reinforcement indicates that the nature of deformation generally corresponds to the test results; however, the yield strength was not achieved in any sample, although experiments showed that it was achieved in samples B1...B4, B6...B8, B11.

In general, conducting such calculations helps predict the nature of destruction and deformation of elements, however, 
among the disadvantages of such a simulation, it should be noted that the whole process of constructing a calculation scheme to analyze the obtained values takes a substantial period of time, and the generally accepted criterion of failure in the software package is not developed and the user independently chooses what to take for the destruction of an element.

a)

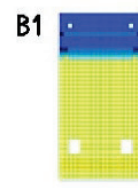

B6
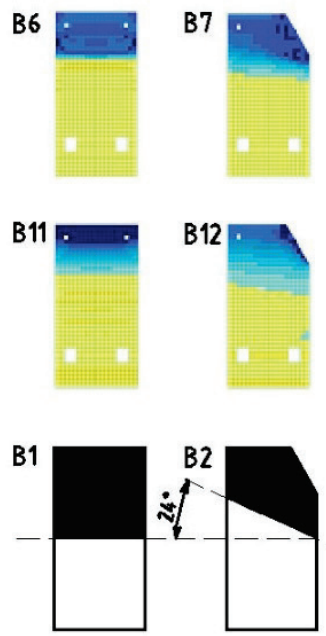

b)
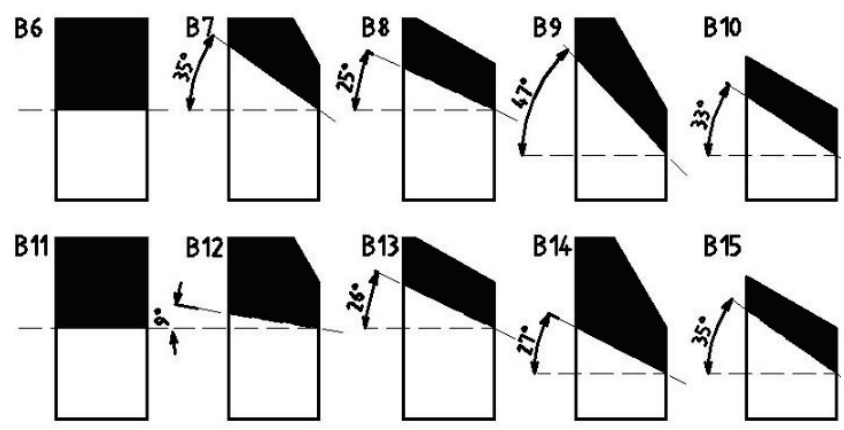

Figure 4 Position of the neutral axis of the cross section of the samples: (a) in the LIRA-CAD program complex and (b) in the laboratory test

The typical character of strain distribution and deflections in the damaged sample B4 is shown in Fig. 5.

\section{PROPOSED METHOD OF THE CALCULATION OF THE INCLINED SECTIONS' DAMAGED BEAMS}

The geometrical characteristics for the calculations for the proposed methodology are shown in Fig. 6. All nonindicated of the furthest methodical values recommended to be adopted by such values are recommended by the codes $[5$, $6]$.

In the current regulations [5, 6], to determine the bearing capacity of the inclined sections, the method of truss analogy is used. According to this method, the bearing capacity $V_{\mathrm{Rd}}$ is defined as:

$$
V_{\mathrm{Rd}}=V_{\mathrm{Rd}, \mathrm{c}}+V_{\mathrm{Rd}, \mathrm{s}}
$$

where $V_{\mathrm{Rd}, \mathrm{c}}$ is defined as the maximum of the Eq. (2) and (3):

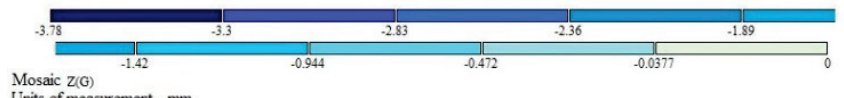

Units of measurement - mm

a)

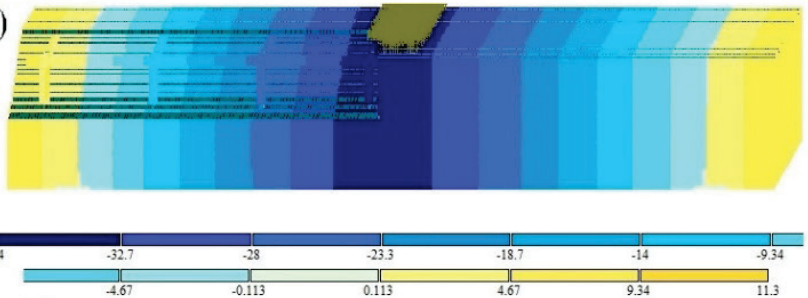

Mosaic Nx

measurement - $\mathrm{MPa}$

b)
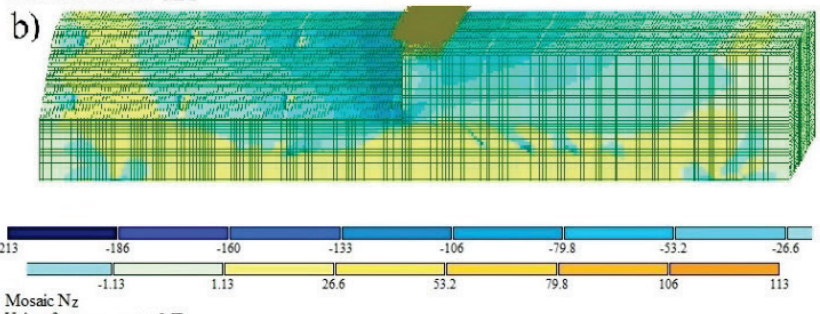

Mosaic $\mathrm{Nz}_{2}$
Units of measurement - $\mathrm{MPa}$

\section{c)}
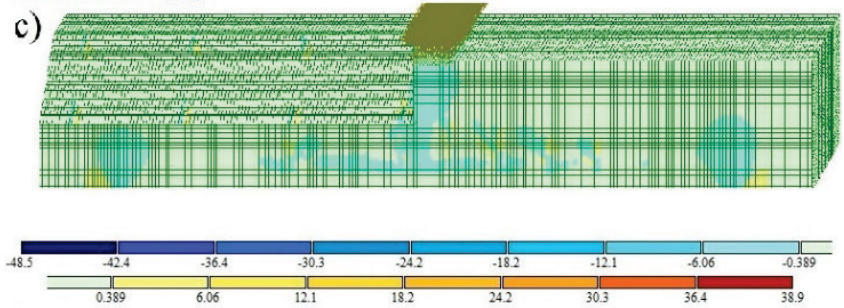

Mosaic Txz

Units of measurement - MPa

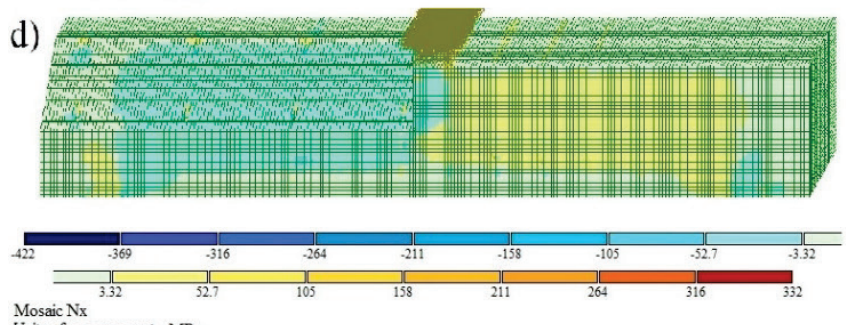

Mosaic Nx
Units of measurement - MPa
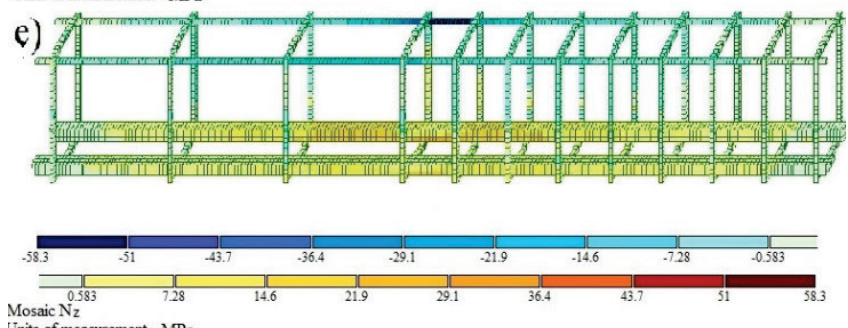

urement - MPa

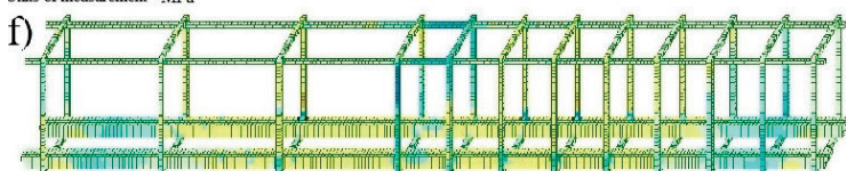

Figure 5 Character of the strain distribution and deflections in the damaged sample B4

$V_{\mathrm{Rd}, \mathrm{c}}=\left(C_{\mathrm{Rd}, \mathrm{c}} \cdot k \cdot \sqrt[3]{100 \cdot \rho_{1} \cdot f_{\mathrm{ck}}-k_{1} \cdot \sigma_{\mathrm{cp}}}\right) \cdot b_{\mathrm{w}} \cdot d$ 


$$
V_{\mathrm{Rd}, \mathrm{c}, \min }=\left(0.035 \cdot k^{\frac{3}{2}} \cdot f_{c k}^{\frac{1}{2}}+k_{1} \cdot \sigma_{\mathrm{cp}}\right) \cdot b_{\mathrm{w}} \cdot d
$$

and the value $V_{\mathrm{Rd}, \mathrm{s}}$ is defined as the minimum of the Eq. (4) and (5):

$$
\begin{aligned}
& V_{\mathrm{Rd}, \mathrm{s}}=\frac{A_{\mathrm{sw}}}{s} \cdot z \cdot f_{y \mathrm{wd}} \cdot \cot \theta \\
& V_{\mathrm{Rd}, \mathrm{s}}=\frac{\alpha_{\mathrm{cw}} \cdot b_{\mathrm{w}} \cdot z \cdot v_{1} \cdot f_{\mathrm{cd}}}{\cot \theta+\tan \theta}
\end{aligned}
$$

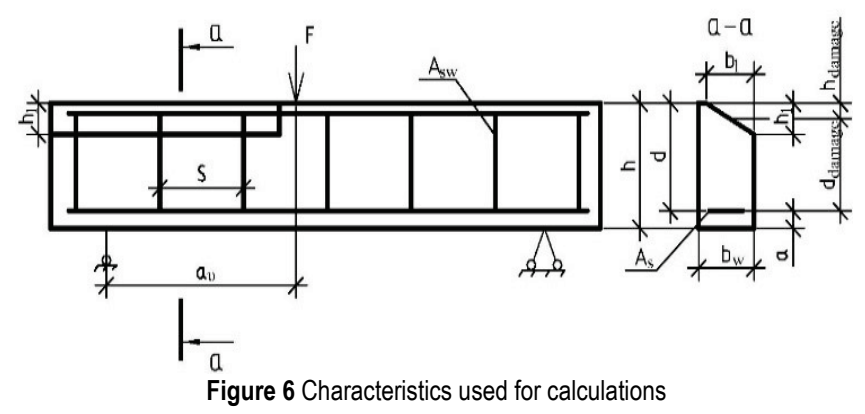

By analyzing the data obtained during the research, it is found that a significant influence on the bearing capacity is exerted by the effect of the shear span - it can be noticed that with decreasing size of the shear, the bearing capacity of the experimental samples span increases by nonlinear dependence. But in the codes, the increasing of the bearing capacity is described by a linear expression:

$\beta=\frac{a_{\mathrm{v}}}{2 d}$

Due to the decrease of the acting shear force $V_{E d}$ by this value, at the shear span in the range of $0.5 d \leq a_{v} \leq 2 d$, whereas at the range of more than $2 d$ it is not taken into account, the results of the experimental studies indicate that the shear span of $a_{v}=3 d$ affects the bearing capacity; in particular, the greatest impact was observed in the undamaged sample (B1) and the sample with the largest damage area (B5) experienced a decrease of up to $32-34 \%$ compared with a similar sample with $a_{v}=2 d$ (B6 and B10, respectively). At the shear span $1 d$, an increase in the strength of the samples exceeds the stated in the Eq. (1).

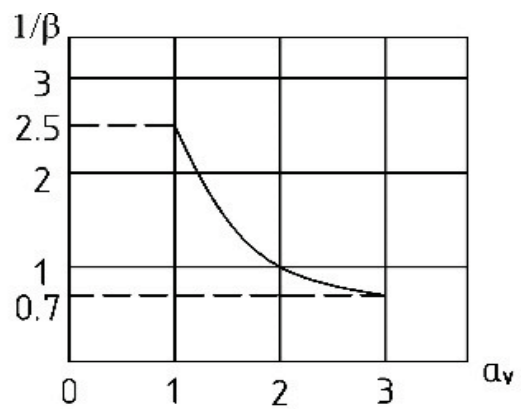

Figure 7 Dependence of $1 / \beta$ of the shear span
When one takes into account the relative shear span (in the studied range of $1 d \leq a_{v} \leq 3 d$ ), it is recommended to determine the dependence of $1 / \beta$ by using Fig. 7 .

Based on the above, the Eq. (1) can be transformed into Eq. (7):

$V_{\mathrm{Rd}}=\left(V_{\mathrm{Rd}, \mathrm{c}}+V_{\mathrm{Rd}, \mathrm{s}}\right) \frac{1}{\beta}$

As the results of experimental studies found that the area of damage affects the residual bearing capacity, in further calculations, it is necessary to introduce a number of changes. Due to the fact that the damaged elements have been calculated and it has been found that the shape of damage is not determinative, but its area is, then the value should be entered in the calculation as an equivalent height of the damage $h_{\text {damage: }}$ :

$h_{\text {damage }}=\frac{A_{\text {damage }}}{b_{\mathrm{w}}}$

Instead of the working height element $d$, the equivalent working height with regard to the damage $d_{\text {damage }}$ should be used:

$d_{\text {damage }}=h-a-h_{\text {damage }}$

The reinforcement ratio for the longitudinal reinforcement $\rho_{1}$ is then determined by the Eq. (10):

$\rho_{1}=\frac{A_{\mathrm{s}}}{b_{\mathrm{w}} \cdot d_{\text {damage }}} \leq 0.02$

The empirical coefficient $k$ is determined by the Eq. (11) $\left(d_{\text {damage }}\right.$ use in $\left.\mathrm{mm}\right)$ :

$k=1+\sqrt{\frac{200}{d_{\text {damage }}}} \leq 2.0$

In this case, in the Eq. (2) and (3), from the cross-sectional area of the element $\left(b_{\mathrm{w}} \cdot d\right)$ the area of the damage must be subtracted, which is denoted as $A_{\text {damage }}$. Considered to be action elements without the longitudinal force, the part $k_{1} \cdot \sigma_{\mathrm{cp}}$ must be ignored. The expressions then take the following form:

$$
\begin{aligned}
& V_{\mathrm{Rd}, \mathrm{c}}=\left(C_{\mathrm{Rd}, \mathrm{c}} \cdot k \cdot \sqrt[3]{100 \cdot \rho_{\mathrm{l}} \cdot f_{\mathrm{ck}}}\right)\left(b_{\mathrm{w}} \cdot d-A_{\mathrm{damage}}\right) \\
& V_{\mathrm{Rd}, \mathrm{c}, \min }=\left(0.035 \cdot k^{\frac{3}{2}} \cdot f_{\mathrm{ck}}^{\frac{1}{2}}\right)\left(b_{\mathrm{w}} \cdot d-A_{\mathrm{damage}}\right)
\end{aligned}
$$

According to the results of the experimental studies, in the Eq. (4) and (5), the angle of the inclined cracks $\theta$ 
respectively to the axe of the beam proposes to take the value of $\cot \theta$ based on the value of the shear span:

$$
\cot \theta=\frac{a_{v}}{d}
$$

The resulting value $\cot \theta$ should be limited to the range between $1 \leq \cot \theta \leq 2.5$.

The lever arm of the internal forces $z$ should be adapted:

$$
z=0.9 \cdot d_{\text {damage }}
$$

According to the proposals, a convenient calculation algorithm is created, which is shown in Fig. 8.

In the proposed method of calculation, test calculations were performed and the results are shown in Tab. 3. A comparison of the results of the calculation showed good convergence with the results of the experiment; the coefficient of variation is $v=10,3 \%$, which indicates the feasibility of using the developed methodology in the practice of design and construction.

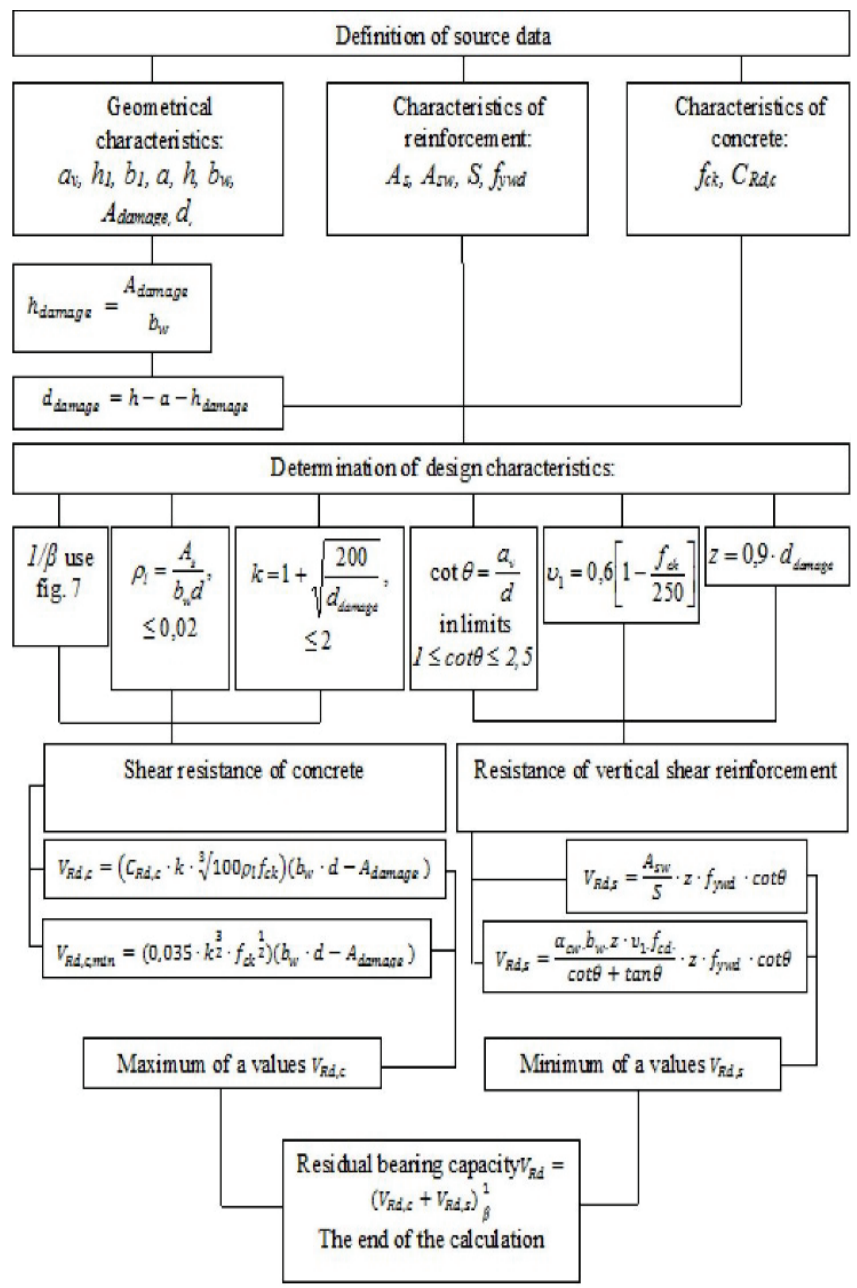

Figure 8 Proposed algorithm of the calculation of the residual bearing capacity of the damaged reinforced concrete beams' inclined sections
List of symbols in the calculation:

$A$ - cross-sectional area

$A_{\text {damage }}$ - total damage area

$A_{\mathrm{S}}$ - cross-sectional area of longitudinal reinforcement

$A_{\text {sw }}$ - cross sectional area of shear reinforcement

$a$ - the axis distance of reinforcing steel from the nearest surface

$a_{\mathrm{v}}$ - shear span

$b_{1}$ - width of the damage on the beam

$b_{\mathrm{w}}$ - width of the web on the beam

$C_{\mathrm{Rd}, \mathrm{c}}$ - value of the shear strength of concrete

$d$ - effective depth of a cross-section

$d_{\text {damage }}$ - equivalent damage depth of a cross-section

$F$ - action

$F_{\mathrm{u}}$ - ultimate action

$f_{\mathrm{u}}$ - ultimate deflection

$f_{\text {ck }}$ - characteristic value of the compressive strength of concrete

$f_{v w d}$ - characteristic yield of shear reinforcement

$h$ - overall depth of a cross-section

$h_{1}$ - damage depth of a cross-section

$h_{\text {damage }}$ - equivalent damage depth of a cross-section

$k$ - coefficient which depends on the effective depth of a cross-section d

$S$ - spacing between shear reinforcement

$V$ - shear force

$V_{\mathrm{Rd}}$ - shear resistance

$V_{\mathrm{Rd}, \mathrm{c}}$ - shear resistance of concrete

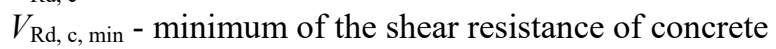

$V_{\mathrm{Rd}, \mathrm{s}}$ - resistance of vertical shear reinforcement

$V_{\mathrm{u}}$ - ultimate shear force

$V_{\mathrm{exp}}^{\mathrm{u}}$ - ultimate shear force of laboratory tests

$V_{\mathrm{LIRA}}^{\mathrm{u}}$ - ultimate shear force of the numerical experiment

$z$ - lever arm of internal forces

$a_{\mathrm{cw}}$ - coefficient of the state of stress in the compression chord

$1 / \beta$ - coefficient which depends on the shear span

$\beta_{1}$ - angle of damage

$\varepsilon_{c}^{\mathrm{u}}$ - ultimate deformations in the concrete

$\varepsilon_{\mathrm{sw}}^{\mathrm{u}}$ - ultimate deformations in shear reinforcement

$v$ - coefficient of variation

$v_{1}$ - strength reduction factor for the concrete cracked in shear

$\rho_{1}$ - reinforcement ratio for longitudinal reinforcement

$\theta$ - angle of the inclined crack

\section{CONCLUSION}

Experimental studies were conducted, and their results determined the residual bearing capacity of the inclined sections and the stress-strain state of the damaged reinforced concrete beams.

It was determined that with a decrease in the shear span, the elements perceive a larger transverse force. The presence of damage leads to a decrease in the bearing capacity, and during destruction, smaller ultimate deflections are reached (because the dangerous crack needs to cross a lower height of the cross-section to destroy the element). The presence of damage also leads to changes in parameters of the stress- 
strain state - a decreasing of the ultimate deformations of the concrete (because of the same reason), an inclination of the neutral axis in the cross section of the element.

Modeling in LIRA-CAD software complex allows to predict the work elements and determine the bearing capacity, but in comparison with the real data, there are still some differences and the process takes considerable time.

The developed method for determining the residual bearing capacity is quite simple to apply, it allows quick calculation and shows good convergence with the experimental data, as indicated by the coefficient of variation $v=10.3 \%$.

\section{REFERENCES}

[1] Bonić, Z., Topličić Ćurčić, G., Davidović, N., \& Savić, J. (2015). Damage of concrete and reinforcement of reinforcedconcrete. Procedia Engineering, 117, 411-418. https://doi.org/10.1016/j.proeng.2015.08.187

[2] Lu, Z., Chai, J., \& Yu. J. (2015). A numerical approach for calculating the mechanical performance of the fire-damaged reinforced concrete continuous beams. Tongji Daxue Xuebao / Journal of Tongji University, 43(1), 16-26. https://doi.org/10.11908/j.issn.0253-374x.2015.01.003

[3] Hayashi, T., Yamauchi, T., Kudoh, H. (1984). Repair Works of the Earthquake Damaged Building by the Nihonkai-Chubu Earthquake, 1983. Concrete Journal, 22, 32-40. https://doi.org/10.3151/coj1975.22.9_32

[4] Ou, Z.-M. \& Sun, L. (2017). Flexural fatigue-life reliability of frost-damaged concrete. Zhejiang Daxue Xuebao (Gongxue Ban) / Journal of Zhejiang University (Engineering Science), 51, 1074-1081 and 1103. https://doi.org/10.3785/j.issn.1008-973X.2017.06.003

[5] BS EN 1992-1-1:2004. Design of concrete structures. General rules and rules for buildings, The European Union Per Regulation 305/2011, Directive 98/34/EC, Directive 2004/18/EC

[6] DBN B.2.6.-98:2009. Concrete and reinforced concrete structures. General rules. Kyiv, 2009, 101 p.

[7] Kabir, M., Subhani, M., Shrestha, R., \& Samali, B. (2018). Experimental and theoretical analysis of severely damaged concrete beams strengthened with CFRP. Construction and Building Materials, 178, 161-174. https://doi.org/10.1016/j.conbuildmat.2018.05.038

[8] Burningham, C., Pantelides, C., Reaveeley, L. (2014). Repair of Prestressed Concrete Beams with Damaged Steel Tendons Using Post-Tensioned Carbon Fiber-Reinforced Polymer Rods. ACI Structural Journal, 111, 387-3954. https://doi.org/10.14359/51686529

[9] Hou, L., Wang, J., Huang, T., Shen, C., Aslani, F., Chen, D. (2019). Flexural behaviour of corroded reinforced concrete beams repaired with ultra-high toughness cementitious composite. Construction and Building Materials, 211, 11271137. https://doi.org/10.1016/j.conbuildmat.2019.03.214

[10] Sakka, Z., Assakkaf, I., \& Qazweeni, J. (2018). Reliabilitybased assessment of damaged concrete buildings. Structural Engineering and Mechanics, 65, 751-760.

[11] Orešković, M., Klymenko, I., Aniskin, A., \& Kozina, G. (2018). Analysis of Damaged Concrete Columns of Circular Cross-Section. Tehnički vjesnik 25(2), 337-343. https://doi.org/10.17559/TV-20160621085905
[12] Klimenko, Y., Chtrnieva, O., \& Ismael, A. (2013). Tests results of the damaged T-section beams. Tehnicki glasnik, 7(4), 344346. https://hrcak.srce.hr/112055

\section{Authors' contacts:}

Zeljko Kos, PhD, Assistant Professor (Corresponding author) University North, Department of Civil Engineering Jurja Krizanica 31B, 42000 Varazdin, Croatia +38598757989, zkos@unin.hr

Yevhenii Klymenko, PhD in Engineering Science, Professor Odessa State Academy of Civil Engineering and Architecture, 4 Didrihsona st., 65029 Odessa, Ukraine klimenkoew57@gmail.com

Kostiantyn Polianskyi, post-graduate student Odessa State Academy of Civil Engineering and Architecture, 4 Didrihsona st., 65029 Odessa, Ukraine kostyapolyanski@gmail.com

Andjelko Crnoja, post-graduate student Odessa State Academy of Civil Engineering and Architecture, 4 Didrihsona st., 65029 Odessa, Ukraine +385992755466, acrnoja@hotmail.com 